\title{
KEPRIBADIAN TOKOH UTAMA DAN NILAI KERJA KERAS DALAM NOVEL RANTAU 1 MUARA KARYA FUADI SERTA RELEVANSINYA DENGAN PEMBELAJARAN APRESIASI SASTRA DI SMA
}

\author{
Wina Yunita, Sarwiji Suwandi, Edy Suryanto \\ Universitas Sebelas Maret \\ Surel:winayunita35@gmail.com
}

\begin{abstract}
Abstrak: Penelitian ini bertujuan mendeskripsikan dan menjelaskan (1) unsur intrinsik;(2) aspek kepribadian tokoh utama;(3) nilai pendidikan karakter; dan(4) relevansi kepribadian tokoh utama dan nilai pendidikan karakter dalam novel Rantau 1 Muara karya Fuadi dengan pembelajaran apresiasi sastra di Sekolah Menengah Atas.Penelitian ini merupakan penelitian deskriptif kualitatif dengan pendekatan psikologi sastra. Teknik pengumpulan data yang digunakan dalam penelitian ini adalah teknik analisis dokumen dan wawancara. Validitas data menggunakan triangulasi data dan triangulasi sumber. Hasil penelitian ini menunjukkan unsur intrinsik yang membangun meliputi: tema pendidikan, alur campuran, latar tempat di Bandung, Jakarta, Maninjau, Amerika, dan Ingrris, penokohan, sudut pandang menggunakan teknik akuan, dan amanat untuk konsisten dalam mengejar cita-cita. Tokoh dan penokohan tokoh utama dalam novel Rantau 1 Muara digambarkan melalui tiga dimensi, yaitu dimensi fisiologis, psikologis, dan sosiologis. Melalui ketiga dimensi tersebut didapatkan penokohan tokoh utama, Alif dan Dinara. Kepribadian tokoh utama dalam novel, dianalisis menggunakan teori psikoanalisis Freud yang meliputi tiga struktur kepribadian Id, Ego, dan Superego. NovelRantau 1 Muara juga mengandung nilai pendidikan kerja keras yang ditemukan pada tokoh utama, Alif dan Dinara. Novel Rantau 1 Muara relevan dengan pembelajaran apresiasi sastra di SMA kelas XII.
\end{abstract}

Kata kunci: psikologi sastra, kepribadian, nilai pendidikan, kerja keras, novel Rantau 1 Muara.

\section{PERSONALITY OF THE MAIN FIGURE AND HARD WORK VALUES IN RANTAU 1 NOVEL BY FUADI AND ITS RELEVANCE AS LEARNING OF LITERATURE APPRECIATION IN SENIOR HIGH SCHOOL}

\begin{abstract}
This study aims to describe and explain (1) the intrinsic element;(2) personality aspect of the main character;(3) character education; and(4) the relevance of the personality of the main character and the value of character education in the novel Rantau 1 Muara Fuadi with learning literature appreciation in High School.This research is a descriptive-qualitative research which used psychology literature approach. The data collection techniques used in this study were document analysis techniques and interviews. The data validity techniques used were data triangulation and source triangulation.The results of this research showed that the structural elements that build include: the theme of education, groove mix, setting a place located in Bandung, Jakarta, Maninjau, America, and England, the personality, the standpoint of using the technique of acknowledgment and the message to consistently pursue ideals.Through the three dimensional character is obtained figures of Alif and Dinara. The personality of the main characters in the novel, analyzed using Freud's psychoanalytic theory which includes three personality structures Id, Ego, and Superego. Novel Rantau 1 Muara also contains the value of hard work education found on the main characters, Alif and Dinara. Novel Rantau 1 Muara is relevant to the learning of literature appreciation in high school class XII.
\end{abstract}

Keywords: literary psychology, personality, value of education, hard work, novel Rantau 1 Muara. 


\section{PENDAHULUAN}

Novel adalah salah satu bentuk dari sebuah karya sastra. Novel merupakan cerita fiksi dalam bentuk tulisan atau kata-kata dan mempunyai unsur intrinsik dan ektrinsik. Sebuah novel biasanya menceritakan tentang kehidupan manusia dalam berinteraksi dengan lingkungan dan sesamanya. Dalam sebuah novel, si pengarang berusaha semaksimal mungkin untuk mengarahkan pembaca kepada gambaran-gambaran realita kehidupan melalui cerita yang terkandung dalam novel tersebut (Hawa, 2013: 21).

Ada beberapa pendekatan yang dapat digunakan untuk mengkaji karya sastra, salah satunya adalah psikologi sastra. Secara definitif, psikologi sastra adalah pemahaman terhadap karya sastra dengan mempertimbangkan aspek-aspek kejiwaannya (Ratna, 2011: 16). Teori psikologi yang sering digunakan dalam melakukan penelitian karya sastra adalah teori psikoanalisis yang dikemukakan oleh Freud. Freud (dalam Prawira, 2013: 186) membedakan kepribadian manusia menjadi tiga unsur kejiwaan, yaitu id, ego, dan super ego.

Karakter adalah kepribadian yang ditinjau dari titik tolak etis atau moral, misalnya kejujuran seseorang yang biasanya mempunyai kaitan dengan sifat-sifat yang relative tetap (Hornby dan Pornwell dalam Banarwi dan Arifin, 2014: 20). Wibowo (2013: 40) menjelaskan bahwa pendidikan karakter adalah pendidikan yang menanamkan dan mengembangkan karakterkarakter luhur kepada peserta didik, sehingga mereka memiliki karakter luhur, menerapkan, dan mempraktikannya dalam kehidupan. Pendidikan karakter dapat pula dimaknai sebagai upaya yang terencana untuk menjadikan peserta didik mengenal, peduli, dan menginternalisasi nilai-nilai sehingga peserta didik berperilaku sebagai insan kamil. Pendidikan karakter juga dapat diartikan sebagai suatu sistem penanaman nilai-nilai karakter kepada warga sekolah yang meliputi komponen pengetahuan, kesadaran atau kemauan, dan tindakan untuk melaksanakan nilai-nilai tersebut baik terhadap Tuhan Yang Maha Esa, diri sendiri, sesama, lingkungan, maupun kebangsaan sehingga menjadi manusia insan kamil (Samani dan Hariyanto, 2012: 46).

Nilai-nilai yang diinternalisasikan dalam pendidikan karakter ada 18, salah satunya adalah nilai pendidikan karakter kerja keras.Kerja keras adalah kemampuan mencurahkan atau mengerahkan seluruh usaha dan kesungguhan, potensi yang dimiliki sampai akhir masa suatu urusan hingga tujuan tercapai. Adapun indikator seseorang itu bekerja dengan ikhlas adalah:

(1) bekerja ikhlas dan sungguh-sungguh, (2) bekerja melebihi target, dan (3) produktif (Wibowo, 2013b: 65). Kerja keras berkaitan dengan etos kerja. Sinamo (2015: 26) mendefinisikan etos kerja adalah seperangkat perilaku positif yang berakar pada keyakinan fundamental yang disertai komitmen total pada paradigma kerja yang integral. Etos kerja diwujudkan menjadi tindakan dengan komitmen yang kuat dan konsisten dalam pelaksanaanya.

Novel Rantau 1 Muara merupakan novel ketiga dari trilogi Negeri 5 Menara. Novel karya Fuadi ini merupakan genre fiksi motivasi dan fiksi pendidikan. Novel ini menceritakan kisah perjuangan Alif Fikri dan Dinara Larasati sebagai tokoh utama yang berjuang hidup menjadi imigran di Amerika. Sebelum Alif dan Dinara menginjakkan kaki di Amerika, telah banyak perjuangan dan pengorbanan kedua tokoh utama ini untuk bisa sampai di Amerika. Setelah sampai di Amerika pun masih banyak perjuangan hingga Alif dan Dinara bisa hidup dengan nyaman dan sejahtera, dan kemudian memilih meninggalkan kenyamanan hidup di Amerika dan bersamsama kembali ke Indonesia untuk mengabdi pada bangsa dan negara (Fuadi, 2010). 
Nilai positif yang bisa kita ambil dalam novel Rantau 1 Muara karya Fuadi adalah karakter kerja keras tokoh utama, yakni Alif Fikri dan Dinara Larasati. Kerja kerasnya untuk mendapatkan pekerjaan, perjuangan untuk melanjutkan study $\mathrm{S} 2$ dan berburu beasiswa, perjuangan untuk bertahan hidup di kota besar Amerika dan jauh dari keluarga dan pilihan untuk kembali ke Indonesia dengan meninggalkan kenyamanan hidup yang bisa didapat di Amerika patut untuk dicontoh.

Berdasarkan ulasan mengenai novel Rantau 1 Muara karya Fuadi yang banyak mengandung nilai pendidikan kerja keras serta kepribadian tokoh utama yang begitu kuat, yang menjadi alasan untuk meneliti novel ini dari segi kepribadian dan nilai pendidikan kerja keras tokoh utama dalam Novel Rantau 1 Muara. Selain alasan tersebut, sebuah penelitian yang dilakukan oleh Fujiastuti (2014) dengan judul "Stilistika dan Nilai Pendidikan dalam Novel Rantau 1 Muara Karya Ahmad Fuadi"dengan hasil penelitian unsur intrinsik dalam novel Rantau 1 Muara dan Nilai Pendidikan yaitu nilai agama, moral, sosial, dan nilai budaya, oleh karena itu peneliti tertarik untuk meneliti novel Rantau 1 Muara dengan subyek yang berbeda yaitu kepribadian tokoh utama dan nilai kerja keras dalam novel Rantau 1 Muara karya Fuadi serta relevansinya dengan pembelajaran apresiasi sastra di SMA.

Tujuan dari penelitian ini adalah mendeskripsikan dan menjelaskan (1) unsur intrinsik; (2) kepribadian tokoh utama; (3) Nilai pendidikan kerja keras yang terdapat dalam novel Rantau 1 Muara; dan (4) relevansi kepribadian tokoh dan nilai pendidikan karakter dalam novel Rantau 1 Muara dengan pembelajaran apresiasi sastra di SMA.

\section{METODE PENELITIAN}

Penelitian ini merupakan penelitian deskriptif kualitatif, dengan data berupa paragraf yang terdapat dalam novel. Sumber data yang digunakan ada 2, sumber data primer dan sekunder. Sumber data primer adalah Novel Rantau 1 Muara karya Fuadi dan buku-buku yang mengacu pada penelitian. Sumber data sekunder adalah data hasil wawancara dengan narasumber. Teknik sampling yang digunakan adalah purposive sampling, dan teknik pengumpulan data ada 3 teknik yaitu teknik baca, teknik catat, dan teknik wawancara. Triangulasi yang digunakan dalam penelitian ini adalah triangulasi data dan teori. Teknik analisis data adalah analisis isi dengan menggunakan pendekatan psikologi sastra.

\section{HASIL DAN PEMBAHASAN \\ Unsur Intrinsik dalam Novel Rantau 1 Muara Karya Fuadi}

Tema yang terkandung dalam novel Rantau 1 Muara adalah tema tentang pendidikan, perjuangan mencapai impian dan menemukan tujuan hidup. Hal tersebut dapat dilihat dalam kutipan berikut.

Mungkin saatnya aku berburu beasiswa lagi. Kali ini untuk gelar S-2. Mungkin pekerjaan yang aku cintai itu sebetulnya menuntut ilmu. Mungkin tujuan yang ingin aku tuju adalah ilmu, dan jalan yang aku lalui adalah belajar. Belajar dari buaian sampai liang lahat. Itu doktrin yang aku dapatkan di Pondok Madani dulu (Fuadi, 2013: 112).

Alur yang digunakan dalam novel ini adalah alur campuran, hal tersebut dikarenakan dalam novel Rantau 1 Muara alur berjalan maju sesuai urutan kejadian, kemudian di tengah cerita, alur menceritakan tentang kejadian masa lalu yang dialami tokoh dalam cerita. Hal tersebut dapat dilihat dalam kutipan berikut. 
"Panjang lagi ceritanya. Saya cerita sambil makan siang ya. Lapar nih mendayung terus" katanya sambal menepikan kano di pinggir sungai yang landau dan rindang (Fuadi, 2013: 216).

Latar tempat yang paling awal ditampilkan dalam cerita adalah kota Bandung. Hal tersebut dapat dilihat dalam kutipan berikut.

Setahun yang telah membuat aku bukan pemuda tahun lalu lagi. Aku yang baru, aku yang sudah berbeda. $I$ am back in Bandung (Fuadi, 2013: 2). Latar tempat berikutnya adalah kota

Jakarta. Hal tersebut dapat dilihat dalam kutipan berikut.

Ketika memasuki Jakarta, dari mobil sewaan ini sesekali kulihat dindingdinding bangunan yang masih menyisakan jelaga sisa kebakaran, jendela yang masih ditutup seng dan tripleks, dan portal-portal besi yang baru di pasang di hampir semua mulut jalan dan gang (Fuadi, 2013: 43).

Latar tempat berikutnya adalah Padang, Sumatera Barat. Hal tersebut dapat dilihat dalam kutipan berikut.

Aku tarik napas dalam ketika kakiku akhirnya menjejak di jalan kecil yang melingkari Danau Maninjau. Aku pulang ke kampung kelahiranku di Bayur untuk meminta restu dan doa Amak (Fuadi, 2013: 173).

Latar tempat berikutnya adalah Amerika. Hal tersebut dapat dilihat dalam kutipan berikut.

Ya Tuhan, ini dia kampus yang akan menjadi tempatku menuntut ilmu selama dua tahun. George Washington University atau singkatannya GWU (Fuadi, 2013: 199).

Latar tempat yang terakhir adalah di Inggris. Hal tersebut dapat dilihat dalam kutipan berikut.
Norak sih, tapi gaya, karena kami berfoto di depan Stadion Wembley, stadion kebanggaan tim sepak bola nasional Inggris (Fuadi, 2013: 372).

Latar waktu pagi dalam novel Rantau 1 Muaradapat dilihat dalam kutipan berikut.

Pagi itu aku ikut duduk di depan TV bersama Ibu Kos yang tidak hentihentinya ngemil kacang (Fuadi, 2013: 121).

Latar waktu siang dalam novel Rantau 1 Muara dapat dilihat dalam kutipan berikut.

Sekeras aku menolak, sekeras itu pula mereka berdua mengajakku untuk mengobrol sambil makan siang di Rumah Makan Saung Sunda (Fuadi, 2013: 26).

Latar waktu sore dalam novel Rantau 1 Muara dapat dilihat dalam kutipan berikut.

Sore itu aku merasa terhina karena membiarkan diriku terancam secara psikologis dan fisik oleh tamu-tamu tak diundang ini (Fuadi, 2013: 37).

Latar waktu malam dalam novel Rantau 1 Muara dapat dilihat dalam kutipan berikut.

Malam tanggal 9 Maret 1998 itu aku begadang menulis surat lamaran dan besok paginya aku sudah sampai di Kantor Pos Besar Bandung untuk mengirimkan surat-surat itu (Fuadi, 2013: 18).

Latar waktu dini hari dalam novel Rantau 1 Muara dapat dilihat dalam kutipan berikut. Lelah membaca, menjelang 2 dini hari, aku kembali ke musala (Fuadi, 2013: 112).

Latar waktu musim dingin dalam novel Rantau 1 Muaradapat dilihat dalam kutipan berikut.

Walau masih terhitung musim dingin, hari ini matahari benderang dan suhu enak untuk jalan-jalan ke luar apartemen. Kami memutuskan untuk makan angin dengan bersepeda (Fuadi, 2013: 378). 
Latar waktu musim semi dalam novel Rantau 1 Muaradapat dilihat dalam kutipan berikut.

Jutaan warga Amerika juga diserang pollen allergy, alergi karena serbuk bunga yang beterbangan di udara musim semi. Jadilah musim semi adalah musim bersin berjamaah (Fuadi, 2013: 304).

Latar waktu musim gugur dalam novel Rantau 1 Muara dapat dilihat dalam kutipan berikut.

Aku rapatkan jaket melawan angin dingin musim gugur dan duduk di kursi kayu di tengah Kogan Plaza (Fuadi, 2013: 260).

Sudut pandang yang digunakan dalam novel adalah sudut pandang orang pertamapelaku utama. Hal ini terlihat pada halaman pertama novel. Penulis menggunakan sudut pandang orang pertama dalam menceritakan kisah dalam novel. Hal tersebut dapat dilihat dalam kutipan berikut.

Aku tancapkan kunci dan kuakkan pintu itu tergesa-gesa. Macet. Tidak beringsut. Hanya anak-anak kunci lain yang bergoyang berdenting-denting. Aku lorotkan ransel tambunku yang seberat batu ke lantai, lalu aku miringkan badan dan aku sorong pintu ini dengan bahu (Fuadi, 2013: 1).

Tokoh utama yang terdapat dalam novel adalah Alif dan Dinara, hal ini dikarenakan dalam novel Rantau 1 Muara tokoh yang paling sering diceritakan adalah tokoh Alif dan Dinara.

Amanat adalah pesan yang terkandung dalam sebuah karya sastra yang ingin disampaikan kepada pembaca. Amanat yang terkandung dalam sebuah karya sastra secara garis besar disampaikan dengan dua cara, yakni secara langsung dan secara tak langsung atau tersirat.

Sejak hari itu, aku mengirim banyak surat lamaran ke berbagai media massa dan penerbit buku. Man saara ala darbi washala (Fuadi, 2013: 31).

Pesan atau amanat yang dapat diambil dalam kutipan di atas adalah, kita harus berikhtiar atau berusaha, kemudian tawakal. Karena ada pepatah arab yang mengatakan man saara ala darbi washala, siapa yang berjalan di jalanNYA pasti akan sampai pada tujuan.

Penelitian ini relevan dengan penelitian yang dilakukan oleh Sunata (2014: 583-593) dengan judul "Tinjauan Struktural dan Nilai Pendidikan Novel Bidadaribidadari Surga Karya Tere Liye: (Relevansinya dalam Pembelajaran di Sekolah Mengah Atas) dalam penelitian yang dilakukan oleh Sunata, dibahas mengenai unsur intrinsik dalam novel Bidadari-bidadari Surga yang terdiri dari, tema, alur, amanat, penokohan, latar, sudut pandang, dan gaya Bahasa. Adapun dalam penelitian ini unsur intrinsik yang dikaji adalah tema, alur, amanat, penokohan, latar, dan sudut pandang.

\section{Kepribadian Tokoh Utama dalam Novel Rantau 1 Muara Karya Fuadi}

Sebuah penelitian yang dilakukan oleh Mehmet (2011: 416) ditemukan bahwa, the structural model of the psyche, or the psychodynamic model of abnormality is a model in which Freudintroduced the id, ego, and super ego as templates for the functioning of the psyche. It is based on the principles that psychological illness comes about from repressed emotions and thoughts from experiences in the past. Maksud dari pendapat tersebut yaitu,model struktural kejiwaan, atau model psikodinamis dari ketidaknormalan adalah seduah model yang mana Freud memperkenalkan id, ego, dan super ego sebagai contoh untuk pemfungsian kejiwaan. Teori psikodinamik berasal dari teori psikoanalisis Freud. Teori Psikoanalisis Freud memusatkan perhatian pada pentingnya pengalaman-pengalaman masa 
kanak-kanak awal. Berdasarkan pendapat diatas bahwa Freud membagi struktur psikis menjadi tiga, yakni id, ego, dan super ego.

\section{Aspek Id tokoh Alif Fikri}

Alif adalah tokoh dengan id yang kuat. Aspek id yang terdapat dalam tokoh Alif adalah keinginan untuk melanjutkan kuliah S2 di luar negeri dan mendapatkan beasiswa. Hal tersebut dapat dilihat dalam kutipan berikut.

Impian kuliah ke luar negeri sering aku ceritakan ke kawan-kawan reporter di saat makan siang (Fuadi, 2013: 156).

Aku bergidik sendiri membayangkan kalau sampai aku tidak jadi berangkat. Bagaimana jadinya impianku yang terlanjur melambung jauh untuk sekolah ke Amerika (Fuadi, 2013: 178).

Kutipan tersebut menunjukkan Alif sangat menginginkan kuliah S2 di luar negeri. Hal ini membuat Alif sempat merasa sedih jika keinginannya tersebut tidak dapat tercapai. Karena impian Alif untuk kuliah di luar negeri sudah melambung tinggi, membuat Alif berusaha dengan maksimal untuk bisa mencapainya. Alif belajar setiap hari dan membawa buku TOEFL ke manamana. Setiap ada waktu luang, Alif menyempatkan untuk membuka dan belajar buku TOEFL yang dibawanya. Hal tersebut dapat dilihat dalam kutipan berikut.

Dengan pelupuk mata yang berat, aku bubungkan doaku terakhir sebelum tidur. Semoga doaku ditiup oleh baling-baling sampai ke langit. Ya Tuhan, mudahkanlah jalanku menuntut ilmu ke negeri orang. Lalu aku telungkupkan buku TOEFL ke mukaku, siapa tahu malam ini isi buku ini mencair dan mengalir pindah ke otakku (Fuadi, 2013: 156).

Kutipan di atas menunjukkan bahwa Alif, sangat menginginkan melanjutkan
Kuliah S2 di luar negeri. Alif sangat ingin jika impiannya bisa tercapai, ia berdoa dan memohon dengan sungguh-sungguh kepada Allah SWT dalam setiap salatnya. Selain berdoa, Alif juga belajar TOEFL setiap sebelum tidur.

\section{Aspek Ego Tokoh Alif Fikri}

Alif memiliki ego yaitu ego untuk mewujudkan keinginannya kuliah S2 di luar negeri dan mendapatkan beasiswa. Di mana untuk dapat meraih beasiswa ke Kanada. Dia meninggalkan kenikmatan-kenikmatan memiliki waktu bersantai dengan temantemannya, berlarut-larut hingga malam untuk belajar, membaca, menulis dan terus mengasah kemampuannya. Hal tersebut dapat diketahui dalam kutipan berikut.

Tentulah aku beruntung. Seandainya dia tau dan merasakan bagaimana aku mengorbankan kenikmatankenikmatan sesaat untuk bisa sampai "beruntung". Berapa ratus malam sepi yang aku habiskan sampai dini hari untuk mengasah kemampuanku, belajar, membaca, menulis, dan berlatih tanpa henti. Melebihi usaha di atas rata-rata orang lain agar bisa meningkatkan harkat diriku (Fuadi, 2013: 8).

Ego Alif untuk mewujudkan keinginannya kuliah S2 di luar negeri membuat dirinya rela meninggalkan kenikmatan-kenikmatan hidup. Alif selalu memaksakan diri untuk belajar meskipun ia dalam keadaan mengantuk dan lelah setelah bekerja. Hal tersebut dapat dilihat dalam kutipan berikut.

Jam 11 malam berdentang, Faizal dan Yansen menyeret kakinya pulang. Aku pun mulai mengantuk dan mataku sepet. Tapi aku paksakan menyelesaikan satu bab latihan TOEFL lagi (Fuadi, 2013: 153).

Ego Alif untuk mewujudkan keinginannya kuliah S2 juga terlihat saat 
Alif berusaha untuk meyakinkan Ibunya, Alif berusaha menjelasakan bahwa kuliah S2 di Amerika tidak akan mempengaruhi keimannya. Hal tersebut dapat dilihat dalam kutipan berikut.

Aku perlu waktu satu jam untuk memberikan penjelasan dan alasanalasanku merantau jauh ke Amerika Serikat. Bahwa di Amerika Utara itu Islam pun berkembang luas. Dan kenapa keimanan dan ideologiku tidak akan berubah walau sekolah di sana (Fuadi, 2013: 175).

Kutipan-kutipan di atas menunjukan betapa besarnya Ego Alif, hal inilah yang membuat Alif begitu semangat dan pantang menyerah dalam meraih impiannya kuliah S2 di luar negeri. Alif sudah terbiasa terjaga sampai dini hari untuk belajar dan melakukan banyak riset untuk mewujudkan impiannya.

\section{Aspek Superergo Tokoh Alif Fikri}

Aspek kepribadian super ego mulai terlihat dari awal cerita. Pada awal cerita Alif adalah seorang lulusan S-1 UNPAD. Pada saat itu adalah saat terjadinya krisis moneter. Dimana-mana terjadi demo untuk menurunkan Presiden Soeharto dari jabatannya. Alif merasa, ikut demo untuk menurunkan kepemimpinan Soeharto adalah tindakan yang sangat mulia. Hal tersebut dapat dilihat dalam kutipan berikut.

Aku lupa kalau sedang flu berat. Bergabung dengan para pendemo untuk menurunkan pemerintah Orde Baru saat itu rasanya bagai berjihad membela Ibu Pertiwi. Heroisme inilah yang menyulut gelombang demi gelombang mahasiwa untuk turun ke jalanan dan menyemut memenuhi kompleks gedung DPR/ MPR (Fuadi, 2013: 21).

Aspek kepribadian super ego, juga terlihat dalam diri Alif ketika dia sangat peduli kepada keluarganya. Setelah ayahnya meninggal, Alif merasa tanggungjawab menjaga dan membantu memenuhi kebutuhan mereka adalah tanggungjawabnya sebagai anak laki-laki tertua. Hal tersebut dapat dilihat dalam kutipan berikut.

Setelah dua minggu menjadi doktor, aku menerima gaji pertama. Untuk pertama kali dalam hidup aku mendapatkan gaji yang langsung ditransfer ke rekeningku. Dalam sekejap Rp 1.250.000 habis aku bagibagi, untuk Amak, adik-adik, utang, biaya makan, dan membeli sepotong pantalon dan kemeja. Hari itu pula, sebelum tidur di kos ruang arsip, dengan resmi aku cabut surat Amak dan adik-adik yang telah kuselipkan di buku harianku sejak berbulan-bulan lalu. Hari ini aku tunaikan kembali tugasku yang sempat tertunda sebagai anak laki-laki dan kakak tertua: membantu mereka secara finansial, sesuai kemampuanku (Fuadi, 2013: 69-70).

Aspek kepribadian super ego, juga terlihat saat Alif menerima uang suap saat ia menjadi wartawan. Alif merasa menerima uang suap adalah perbuatan yang tidak baik dan melanggar prinsipnya, sehingga Alif mengembalikan uang suap tersebut setelah acara selesai. Hal tersebut dapat dilihat dalam kutipan berikut.

Setelah acara selesai aku menemui laki-laki bersafari tadi. Ragu sejenak, tapi akhirnya aku mengangsurkan juga amplop itu kembali ke dia. "Maaf Pak, saya gak usah" (Fuadi, 2013: 61).

\section{Aspek Id Tokoh Dinara Larasti}

Jika dilihat dari aspek id, Dinara yang sejak lahir sampai kuliah dan bekerja belum pernah merantau, sangat menginginkan untuk merantau mencari pengalaman hidup. Hal tersebut dapat dilihat dalam kutipan berikut. 
"Dari lahir sampai kuliah dan kerja, ya tetap tinggal di rumah yang sama, bahkan di kamar yang sama. Ingin rasanya bisa keluar dari sarang. Terbang jauh mencari pengalaman" (Fuadi, 2013: 158).

Aspek $i d$ pada diri Dinara juga terlihat dari bagaimana Dinara memimpikan untuk dapat melanjutkan study di London. Dinara ingin belajar tentang kehidupan dengan berkeliling dunia. Hal tersebut dapat dilihat dalam kutipan berikut.

"Maksud Abang gimana? Sekolah di London kan impian Dinara dari dulu. Meskipun hubungan kita juga masa depan. Tapi sekolah S-2 di UK Cuma setahun" (Fuadi, 2013: 258).

Keinginan Dinara untuk melanjutkan kuliah di London juga diketahui oleh Alif. Hal tersebut menmbah keyakinan, bahwa Dinara sangat ingin melanjutkan kuliah di London. Hal tersebut dapat dilihat dalam kutipan berikut.

Aku juga mulai mencari informasi tentang beasiswa di kampus. Aku tahu Dinara juga punya mimpi melanjutkan sekolah di luar negeri (Fuadi, 2013: 211).

\section{Aspek Ego Tokoh Dinara Larasati}

Aspek ego dalam diri Dinara terlihat saat ia akhirnya memberikan kode kepada Alif untuk meneleponnya saat di Amerika. Sebelumnya Dinara sempat mendiamkan Alif beberapa hari sebelum Alif berangkat ke Amerika. Namun karena tidak ingin kehilangan momen, akhirnya Dinara menuliskan pesan agar Alif meneleponnya. Hal tersebut dapat dilihat dalam kutipan berikut.

Baru tiga langkah aku berlalu, tibatiba aku mendengar ketukan di kaca. Aku berbalik. Dia terburu-buru merobek sehelai kertas dari block note-nya, menuliskan sesuatu, dan menempelkannya ke kaca pembatas kami. Tulisan itu jelas dan besar.

"Call me!" Beberapa detik kemudian

dia dia melipat kertas itu dan menyelipkan di antara rongga pintu kaca ke tanganku (Fuadi, 2013: 195). Aspek kepribadian ego pada diri

Dinara juga terlihat saat resepsi pernikahannya dengan Alif. Dinara ingin acara resepsi pernikahannya meriah, sehingga ia bersikeras untuk menggunakan adat Minang saat resepsi dengan alasan adat Minang lebih heboh untuk resepsi. Hal tesebut dapat dilihat dalam kutipan berikut.

Sebagai anak campuran Jawa-Minang, Dinara sebetulnya bisa memilih acara resepsi dengan adat Jawa. Tapi dia sendiri yang bersikeras menggunakan adat Jawa untuk akad nikah, dan adat Minang untuk resepsi. "Gaya Minang itu lebih heboh, lebih warna-warni, lebih asyik untuk resepsi. Kalo adat Jawa cocoknya untuk akad nikah yang syahdu", alasannya beberapa minggu lalu, (Fuadi, 2013: 273).

Aspek kepribadian ego pada Dinara juga terlihat saat Dinara teguh dengan keinginannya pulang ke Indonesia. Dinara terus memberikan alasan-alasan mengapa mereka harus pulang ke Indonesia. Hal tersebut dapat dilihat dalam kutipan berikut.

"Kenapa harus Indonesia? Kalau mau bermanfaat, di sini juga bisa". "Kan Abang sendiri yang pernah bilang, sebaik-baiknya manusia itu yang bermanfaat buat orang lain. Yang paling perlu manfaat itu ya Indonesia. Bangsa kita". Dia tiba-tiba jadi nasionalis tulen. Dia meneruskan, "Lagi pula, kita tidak akan jadi siapa pun yang besar di sini. Kita memang bisa hidup enak dan makmur, tapi kita tetap saja imigran" (Fuadi, 2013: 329).

Aspek Superergo Tokoh Dinara Larasati

Aspek kepribadian super ego pada diri

Dinara terlihat saat ia sedang berseteru dengan Alif. Dinara langsung meminta maaf 
pada Alif, dan mengatakan agar Alif tidak pergi saat mereka sedang berselisih, karena Dinara beranggapan bahwa permasalahan itu harus segera diselesaikan bukan dihindari. Hal tersebut dapat dilihat dalam kutipan berikut.

"Maafkan Dinara juga, Abang. Jangan pergi lagi kayak tadi. Kita selesaikan masalah kita dulu, jangan lari". Balasnya berbisik, (Fuadi, 2013: 295). Aspek kepribadian super ego pada

Dinara terlihat saat ia memberikan alasan kepada Dinara dan Alif harus kembali ke Indonesia. Karena bagi Dinara harta dan kenyamanan hidup yang mereka dapatkan di Amerika akan habis ketika mereka mati, harta bukanlah segalanya. Hal tersebut dapat dilihat dalam kutipan berikut.

"Bang, cobalah pikir lebih panjang. Apa yang akan kita dapatkan di sini akan habis ketika mati. Apa yang kita nikmati ini hanya untuk diri sendiri. Saatnya untuk lebih bermanfaat" (Fuadi, 2013: 328).

Aspek kepribadian super ego pada Dinara terlihat pada saat ia menasehati Alif agar tetap bersabar ketika mendapatkan cobaan. Hal tersebut dapat dilihat dalam kutipan berikut.

"Kan Abang sendiri yang selalu mengingatkan untuk man shabra zhafira kalau dapat cobaan" (Fuadi, 2013: 356).

Penelitian ini relevan dengan penelitian yang dilakukan oleh Ingham (2007: 753-768) dengan judul "The Superego, narcissism and Great Expectations" yang membahas tentan superego pada tokoh dalam novel Great Expectations Charles Dickens, sedangkan penelitian ini membahas id, ego, dan superego pada tokoh utama dalam novel Rantau 1 Muara karya Fuadi.

Penelitian selanjutnya dilakukan oleh Liang (2011: 177-181) dengan judul "The Id, Ego and Super-ego in Pride and Prejudice" yang membahas tentang kepribadian, yaitu $i d$, ego, dan superego yang ada dalam karakter utama Elizabeth. Perbedaan penelitian ini dengan penelitian yang dilakukan oleh Liang terletak pada objek kajian. Objek kajian dalam penelitian ini adalah tokoh utama dalam novel Rantau 1 Muara, sedangkan objek penelitian Liang adalah tokoh utama dalam novel Elizabeth. Selain itu perbedaan lainnya terletak pada fokus penelitian, jika Liang fokus penelitiannya pada kepribadian $i d$, ego, dan superego tokoh utama dalam novel, penelitian ini selain fokus pada kepribadian tokoh utama dalam novel juga mengkaji nilai pendidikan karakter, yaitu nilai pendidikan kerja keras pada tokoh utamanya.

\section{Nilai Pendidikan Kerja Keras dalam Novel Rantau 1 Muara Karya Fuadi}

Sinamo (2015: 99) menyederhanakan teori etos kerja menjadi empat pilar teori utama. Keempat pilar inilah yang bertanggung jawab menopang semua jenis dan sistem keberhasilan yang berkelanjutan pada semua tingkatan. Keempat elemen itu lalu dikonstruksikan dalam sebuah konsep besar yang disebut sebagai Catur Dharma Mahardika (bahasa Sansekerta) yang berarti Empat Darma Keberhasilan Utama, yaitu:

(1) mencetak prestasi dengan motivasi superior, (2) membangun masa depan dengan kepemimpinan visioner, (3) menciptakan nilai baru dengan inovasi kreatif, (4) meningkatkan mutu dengan keunggulan insan.

\section{Nilai pendidikan kerja keras tokoh Alif}

Kerja keras yang terdapat pada tokoh Alif adalah ketika Alif sangat bersemangat untuk menulis. Alif bekerja menjadi seorang penulis dengan penuh semangat untuk memenuhi kebutuhannya dan membantu Amak dan adik-adiknya di kampung halaman. Hal tersebut dapat dilihat dalam kutipan berikut. 
Kini setiap tulisan yang keluar dari kamarku adalah tulisan yang pasti dimuat. Semangat menulisku semakin menggebu-gebu, apalagi belakangan aku juga sering menjadi juara lomba karya tulis level nasional (Fuadi, 2013: 12).

Karena sangat bersemangat, Alif sampai terbangun sebelum azan Subuh dan langsung bersiap untuk berangkat kerja di hari pertama. Hal tersebut dapat dilihat dalam kutipan berikut.

Saking bersemangatnya, aku tersentak bangun sebelum azan Subuh. Aku sisir rambut licin-licin. Aku linting lengan kemeja dan aku cangklongkan sebuah ransel. Ini hari pertamaku masuk kerja (Fuadi, 2013: 61).

Nilai pendidikan kerja keras pada tokoh Alif, terlihat saat Alif kerja dengan disiplin Alif terlihat begitu sibuk melakukan liputan dengan tertib dan teratur. Hal tersebut dapat dilihat dalam kutipan berikut.

Tanggal 11 September 2001 ini menjadi hari tersibuk aku dan Dinara di kantor. Setelah melakukan liputan ke Pentagon dan rumah sakit yang merawat korban di Pentagon, kami kembali ke newsroom. Lalu bersama teman-teman lain kami lintang pukang bergantian siaran dan melaporkan kabar terkini ke segala penjuru Indonesia. Sebaliknya belasan stasiun televisi dan radio di Tanah Air tak henti-henti meminta kami memberikan laporan terbaru (Fuadi, 2013: 337).

Nilai pendidikan kerja keras pada tokoh Alif terlihat saat Alif Bekerja dengan tangguh dan pantang menyerah ia berusaha sekuat tenaga untuk melakukan wawancara dengan petinggi TNI yang anti wartawan. Hal tersebut dapat dilihat dalam kutipan berikut.

"Ini bukan ruang publik. Anda tidak bisa asal tunggu saja di sini".
"Tapi Jenderal adalah pejabat publik. Rakyat berhak bertemu dengan pejabat negara. Kalau memang tidak ada kursi, saya akan duduk di lantai saja Pak" kataku sambil menggelesot di lantai ubin. Aku yakin jenderal ini tidak akan ke mana-mana, karena mobil dinasnya, jip Land Rover all wheels drive hijau, tegak gagah di depan lobi, beberapa meter di depanku. (Fuadi, 2013: 115).

\section{Nilai pendidikan kerja keras tokoh Dinara}

Nilai pendidikan kerja keras pada tokoh Dinara dapat dilihat ketikaDinara bekerja sebagai wartawan. Saat sedang sibuk-sibuknya, Dinara sampai harus bolakbalik ke lapangan untuk melakukan investigasi kemudian langsung membuat laporan dan melaporkannya secara langsung kepada masyarakat. Hal tersebut dapat dilihat dalam kutipan berikut.

Tanggal 11 September 2001 ini menjadi hari tersibuk aku dan Dinara di kantor. Setelah melakukan liputan ke Pentagon dan rumah sakit yang merawat korban di Pentagon, kami kembali ke newsroom. Lalu bersama teman-teman lain kami lintang pukang bergantian siaran dan melaporkan kabar terkini ke segala penjuru Indonesia. Sebaliknya belasan stasiun televisi dan radio di Tanah Air tak henti-henti meminta kami memberikan laporan terbaru (Fuadi, 2013: 337).

Nilai pendidikan kerja keras juga terlihat pada Dinara, saat ia dengan sungguh membuat laporan. Setelah Dinara selesai mewawancarai narasumber, untuk mendukung laporan dari hasil wawancara maka seorang wartawan harus melakukan riset. Hal tersebut dapat dilihat dalam kutipan berikut. 
Tugas kami selanjutnya adalah melakukan riset perpustakaan untuk mendalami latar sejarah Indonesia tahun 1965 dan bagaimana Pemerintah Amerika melihat Indonesia saat itu (Fuadi, 2013: 284).

Nilai pendidikan kerja keras pada Dinara juga terlihat dari komitmen Dinara untuk tetap memberikan laporan terbaru dalam kejadian 11 September yang meruntuhkan dua menara kembar Amerika ditunjukan oleh Dinara dengan komitmennya untuk terus meliput dalam keadaan tubuh telah sangat lelah. Hal tersebut dapat dilihat dalam kutipan berikut.

Kami baru bisa pulang dari kantor jam 10 malam dengan tubuh serasa remuk. Itu pun aku membawa pulang kamera untuk liputan langsung besok pagi (Fuadi, 2013: 337).

Penelitian selanjutnya dilakukan oleh Priansa dan Granida (2015: 342-347) dengan judul "Pengaruh Kepemimpinan Visioner dan Etos Kerja terhadap Kinerja Pegawai Bank Syariah Mandiri" yang membahas tentang pengaruh kepemimpinan visioner terhadap kinerja pegawai dan pengaruh etos kerja terhadap kinerja pegawai. Populasi dalam penelitian ini adalah pegawai Bank Syariah Mandiri di salah satu Kantor Cabang di Kota Bandung sebanyak orang pegawai. Berbeda dengan penelitian ini, penelitian ini menganalisis nilai pendidikan kerja keras dengan objek kajian tokoh utama dalam novel Rantau 1 Muara karya Fuadi.

Relevansi Kepribadian Tokoh Utama dan Nilai Pendidikan Kerja Keras dengan Pembelajaran Apresiasi Sastra di SMA

Relevansi kepribadian tokoh utama dan nilai pendidikan kerja keras dengan pembelajaran apresiasi sastra di SMA, peneliti melakukan wawancara dengan sejumlah narasumber, yaitu Ibu Lathifah Arub Sukmawati, S. Pd,. Menurut informan pertama dalam novel tersebut pembaca diajak untuk optimis dalam melihat masa depan, dan bersemangat dalam mencapai cita-cita. Selain itu, novel Rantau 1 Muara banyak ditemukan nilai positif yang dapat diteladani oleh pembaca dari karakter dan kepribadian tokoh utama Alif dan Dinara. Karakter dan kepribadian tokoh utama Alif dan Dinara yang bisa diteladani antara lain sikap jujur, pantang menyerah, disiplin, optimis, religius, berprestasi, dan lain sebagainya. Selain itu materi pembelajaran tentang apresiasi sastra juga terdapat dalam kurikulum 2013 SMA kelas XII semester II pada (KD) kompetensi dasar (3.1) memahami struktur dan kaidah teks novel baik melalui lisan maupun tulisan; (3.3) menganalisis teks novel baik melalui lisan maupun tulisan.

\section{SIMPULAN}

Dari pemaparan di atas, maka dapat disimpulkan bahwanovel Rantau 1 Muara karya Fuadi memiliki tema pendidikan. Cerita dalam novel karya Fuadi ini menggunakan alur campuran. Latar tempat yang ditemukan dalam novel yaitu, kota Bandung, Jakarta, Padang, Amerika, dan Inggris. Latar waktu yang ditemukan dalam novel yaitu, latar waktu pagi, siang, sore, malam, dan dini hari. Latar waktu musim yang digunakan dalam novel yaitu, musim dingin, musim gugur, dan musim semi. Tokoh utama dalam novel adalah Alif Fikri dan Dinara Larasati. Sudut pandang yang digunakan dalam menceritakan novel Rantau 1 Muara karya Fuadi adalah sudut pandag orang pertama pelaku utama. Amanat yang paling dominan ada pada novel Rantau 1 Muara karya Fuadi, yaitu man saara ala darbi washala, siapa yang berjalan di jalanNYA pasti akan sampai pada tujuan, sehingga kita harus menjadi hamba yang selalu berikhtiar dan berusaha dengan maksimal untuk dapat mencapai tujuan hidup dan cita-cita yang diimpikan. 
Aspek kepribadian dalam kedua tokoh utama berdasarkan teori psikoanalisis Freud, yaitu ditemukan aspek id, ego, dan superego tokoh utama dalam novel Rantau 1 Muara karya Fuadi. Adanya nilai Pendidikan karakter kerja keras dalam tokoh utama Alif Fikri dan Dinara Larasati dalam novel Rantau 1 Muara dalam memperjuangkan cita-citanya. Berdasarkan hasil wawancara yang dilakukan oleh peneliti untuk menguji relevansi hasil temuan penelitian dengan

\section{REFERENSI}

Barnawi dan M. Arifin. (2014). Strategi dan Kebijakan Pembelajaran Pendidikan Karakter. Yogyakarta: Ar-Ruzz Media.

Fuadi, A. (2010). Rantau 1 Muara. Jakarta: PT Gramedia Pustaka Utama.

Fitriana, Y. Atmazaki dan Thahar, H. E. Pendidikan Karakter dalam Novel Negeri 5 Menara Karya Ahmad Fuadi dan Novel Laskar Pelangi Karya Andrea Hirata: Tinjauan Sosiologi Sastra. Jurnal Bahasa, Sastra, dan Pembelajaran. 1 (1), 64-79.

Hawa, M. (2013). "Novel Sepatu Dahlan Karya Khrisna Pabhicara Analisis Psikologi Sastrsa dan Nilai Pendidikan". Jurnal Acarya. 2 (2), 2026.

Ingham. G. (2007). "The Superego, Narcissism and Great Expectations". International Journal Psychoanal, 88 (1), 753-768.

Liang, Y. (2011). "The Id, Ego and Super Ego in Pride and Prejudice". International Education Studies, 4 (2), 177-181.

Mehmet, R. T. A. S. (2011). “Kate Chopin's The Awakening in The Light of Freud's Structural Model of The Psyche". The Journal of International Social Reserch, 4 (19), 413-418. pembelajaran apresiasi sastra di SMA, peneliti melakukan wawancara kepada 3 narasumber, yaitu Lathifah Arub Sukmawati S. Pd. (guru), Aisyah Yuri Oktavania (siswa), dan Adeela Krisaning Dyah (siswa) dapat disimpulkan bahwa kepribadian dan nilai pendidikan kerja keras yang terkandung dalam novel Rantau 1 Muara karya Fuadi relevan dengan pembelajaran apresiasi sastra di SMA.

Minderop, A. (2010). Psikologi Sastra. Karya Sastra, metode, Teori, dan Contoh Kasus. Jakarta: Yayasan Pustaka Obor Indonesia.

Prawira, P. A. (2013). Psikologi Pendidikan dalam Prespektif Baru. Yogyakarta: Ar-Ruzz Media.

Priansa, D. J dan Garnida, A. (2015). Pengaruh Kepemimpinan Visioner dan Etos Kerja terhadap Kinerja Pegawai Bank Syariah Mandiri. Jurnal Ecodemica. 3 (1), 342-347.

Ratna, N. K. (2011). Antropologi Sastra: Peranan Unsur-unsur Kebudayaan dalam Proses Kreatif. Yogyakarta: Pustaka Pelajar.

Samani, M. dan Hariyanto. (2012). Konsep dan Model Pendidikan Karakter. Bandung: Pustaka Pelajar.

Sinamo, J. (2015). Delapan Etos Kerja Profesional. Jakarta: Institut Mahardika.

Sunata, Y. N. (2014). "Tinjauan Struktural dan Nilai Pendidikan Novel BidadariBidadari Surga Karta Tere Liye: (Relevansinya dalam Pembelajaran di Sekolah Menengah Atas)". Jurnal Bahasa, Sastra Indonesia dan Pengajarannya, 1 (3), 583-593.

Wibowo, A. (2013b). Pendidikan Karakter Di Perguruan Tinggi. Yogyakarta: Pustaka Pelajar. 